\title{
Construction management of petrochemical process pipeline installation
}

\author{
Guoqiang Qin¹, Hongge Ding², Xiaohong Liu ${ }^{3}$, Haijun Zhang ${ }^{4}$, Guibao Ma ${ }^{5}$ \\ ${ }^{1}$ Henan University of Urban Construction, Shijiazhuang, Hebei Province, 050000 \\ ${ }^{2}$ Hebei Polytechnic University, Shijiazhuang, Hebei Province, 050000 \\ ${ }^{3}$ Hebei University Of Science and Technology, Shijiazhuang,Hebei Province, 050000 \\ ${ }^{4}$ Shijiazhuang Tiedao University, Shijiazhuang, Hebei Province, 050000 \\ ${ }^{5}$ University Of Chongqing, Shijiazhuang, Hebei Province, 050000
}

\begin{abstract}
The petrochemical pipeline installation project is a very complicated project, each link must abide by the construction plan strictly to ensure the smooth operation of the petrochemical process pipeline and the safe operation of the pipeline.However, from the current situation, there are many problems during the installation of petrochemical process pipeline.To solve these problems effectively, we must choose a scientific and rational method, a clear management of the content, a comprehensive consideration of the problem and deal with the problem in time to improve the installation efficiency of petrochemical pipelines and promote the rapid development of petrochemical technology.
\end{abstract}

Keywords: Petrochemical pipeline; installation project; construction management

\section{Introduction}

With the continuous development of our economy, the petrochemical industry plays a major role in our market economy, providing resources for economic development, clarifying the key contents of petrochemical technology and laying a solid foundation for the efficient operation of the system. In the petrochemical process implementation, the pipeline is an important part of the process of chemical industry, in order to ensure the quality of petrochemical process pipe installation, it is necessary to improve the speed of pipeline operation, especially for the petrochemical engineering with higher risk factor, the safety quality and effectiveness should be guaranteed.

\section{The characteristics of petrochemical process piping installation engineering}

Petrochemical process pipeline and plays an important role in the process of petrochemical process transportation.There are obvious differences between the installation and treatment of such petrochemical pipelines in the installation and treatment of other traditional pipelines in the construction industry. The installation of petrochemical pipelines is very tedious and complicated and requires careful planning and management. In order to petrochemical process pipe installation and processing to scientific standards, it is necessary to fully implement the various processes and control.In the process of installation of petrochemical process pipeline, it has it's certain particularity.First, it requires high standards in the selection of materials in petrochemical pipeline, the petrochemical pipeline must accord with the petrochemical process, to prevent corrosion, in order to avoid in the process of petroleum transportation and raw materials of chemical reaction, reducing the durability of raw materials, so it is necessary to enhance its sustainability.Second, the

Copyright (C) 2018 Guoqiang Qin et al.

doi: $10.18063 /$ scr.v2i 2.424

This is an open-access article distributed under the terms of the Creative Commons Attribution Unported License

(http://creativecommons.org/licenses/by-nc/4.0/), which permits unrestricted use, distribution, and reproduction in any medium, provided the original work is properly cited. 
petrochemical process pipe installation from the welding aspects of a reasonable control, once there are welding problems, it will bring out impurities in the welding aspect, easily have a chemical reaction witn the relevant transport materials.Thus it will bring some influence on the integrity of the whole operation of petroleum process ${ }^{[1]}$. Petrochemical pipeline sophistication is not enough, there will be leakage, which requires the welding operation can be efficient operation of all aspects of the operation of a reasonable standard in order to achieve the ideal goal of petrochemical process.Thirdly, from the aspect of the application of petrochemical process pipelines, the scale of petrochemical process pipelines is usually very large, and it is very extensive in the area of pipeline installation and laying. It needs to take full control of the entire petrochemical process area, in order to avoid a detail problem at a certain stage. For the pipeline connection or cross-cutting issues, we should focus on the discussion to improve the stability of petrochemical pipelines and patency effect.In order to complete the petrochemical process piping installation work, we should not only control the quality strictly ,but also avoid quality problems that may exist, should consider the safety, process and other issues, if these respects are not under reasonable control, it will bring serious influence to the construction quality of installation engineering. This requires the relevant managers to strengthen communication and communication between various departments, and put the management work into practice.

\section{Problems in the construction of petrochemical pipeline installation project}

During the construction process of petrochemical process piping installation, in order to better improve the management level, we must strictly control the existing problems and influence, and discuss its influence, so as to provide references for later petrochemical process piping installation engineering construction management. At the present stage, there are common problems in the construction of the installation project:

\subsection{The survey work is not careful}

In order to put the construction management of petrochemical pipe installation project into place better, the preliminary survey of the construction site is very important.This preliminary survey work will mainly provide favorable reference for later construction, and to a certain extent, avoid hidden dangers in construction $\operatorname{sites}^{[2]}$.

\subsection{Improper selection of pipe materials}

In the construction process of petrochemical pipe installation, it is very important to select the appropriate pipe material. Once the inappropriate pipe material is selected, the construction effect of the later project will be seriously affected. According to the current petrochemical process piping material selection on it, which also has a lot of problems, such as not to carry out a full range of products in petrochemical process understanding and exploration, pipeline material which choosed is easy to produce chemical reaction with petrolrum transport process materials, thus brought a serious threat to the reliability of the later period of transportation .

\subsection{Welding operation is not standard}

In the petrochemical process pipe installation process, reasonable welding operation is a very important stage, once the welding operation is unreasonable, it will be prone to more obvious quality problems, trigger many factors. The most common problem occurred during the operating process of welding operation is the man-made operation, the main reason is because the welder's understanding of the related welding process and standard standard is not enough, so the welding personnel flaws and negligence tend to occur in the operation process, and can not effectively solve and research on welding area, the detailed time and the strength of welding are not thorough enough, thus a larger problem of safety and quality is formed. In addition, for the implementation of the work of welding operation, welding operation of installation construction of the pipeline is also reflected in the external factors, such as ambient humidity is not suitable for welding operation, the result of welding is not accurate enough, and the accuracy of the corresponding welding area is low, and the leakage occurs ${ }^{[3]}$. 


\subsection{Pipe anticorrosion treatment is not in place}

In the process of specific installation and construction of petrochemical process pipelines, anti-corrosion treatment is also a key link, and it is also a prerequisite to ensure that petrochemical process pipelines can be used for a long time in the later stage. The security problems and security risks caused in this process are also very obvious.For the practical application of this kind of petrochemical pipeline anti-corrosion treatment method, it is mainly reflected in the selection of anti-corrosion measures is very unreasonable, the effect is not very obvious.At the present stage, there are many specific corrosion protection methods and technical means in process piping installation. We need to make reasonable selection according to the specific petrochemical operation environment. Once there are problems on the selection, it will directly affect the effect of anticorrosion.It is very difficult to achieve the ideal protective effect if most pipes only use the method of sacrificial anode protection, and it is very easy to cause corrosion.In view of these specific anti-corrosion techniques, the safety problems caused by unreasonable operation in the actual operation are also very obvious. For example, the use of anti-corrosion pigments can not be completely applied in the specific operation flow, there are significant differences in the thickness and uniformity of it, then it will bring certain influence to install to the petrochemical process pipeline, reduce the durability of pipelines.

\section{Measures to solve the construction management of petrochemical process pipeline installation project}

In the petrochemical process pipe installation process, we should put the construction management in place, and emphatically reflect the key points that affect the pipe installation project and control it. The measures to solve the construction management of the petrochemical process pipe installation project include the following.

\subsection{Do a good job of detailed investigation and data collection}

In order to manage construction installation of petrochemical pipelines, it is necessary to reflect the ideal goal of the project. In addition to strict control over specific construction operations, adequate preparations must be made for pre-construction work to ensure that staff can make detailed Site survey records and data collection.The on-site survey of petrochemical process pipeline installation project aims at strengthening the staff's control and understanding of the pipeline installation area and having a general understanding and analysis on the performance of various aspects of the construction site, for example,take an examination of the bearing capacity of soil structure and the internal structure of soil, the degree of corrosion, water content assessment, to study if the site can adapt to the laying of the pipeline land, thus becoming the best pipeline laying ways to ensure that it has the ideal value ${ }^{[4]}$.

\subsection{Proper selection of pipe materials}

Petrochemical process piping materials will directly affect the quality of pipeline installation engineering. Once the quality and quality of pipeline materials are in question, it will bring certain influence to the project schedule.In this regard, in the choice of pipeline materials, we must ensure that the quality of the pipeline material must be qualified, can reflect the coordination and matching in the actual installation process, all aspects of continuity can be smooth, to avoid unnecessary trouble, thus form a reasonable scale of the system.Also, we must focus on the main material of the pipe material to conduct a rigorous review and discussion, making the process of pipe materials and petrochemical products can form a good independent effect, to avoid the possibility of chemical reaction between the two. And we should discuss the internal and external factors to highlight the sturdiness of the pipe material. Finally, in the process of installing pipelines, we should also control the quality of pipelines, ensure the quality of pipelines, identify problems and deal with them in time, so as to avoid substandard products mixed into pipeline installation works.

\subsection{Specification of pipeline welding operation process}

In the installation of petrochemical pipe welding, it also need to strictly control the welding process, petrochemical pipe welding process is mainly to make the operation process more standardized, making the pipe welding area can 
achieve the desired effect of tightness, no fracture and concave problem.

\subsection{Strengthen pipeline anti-corrosion treatment}

After the completion of the petrochemical pipeline installation project, the corresponding corrosion prevention and treatment technology should also be perfected and implemented.To improve the corrosion resistance treatment technology is to strengthen the durability of the process pipeline, and can better deal with all kinds of safety hidden dangers in the later petrochemical process pipeline.

\section{Conclusion}

To sum up, with the continuous development of China's economy, the petrochemical industry occupies the main position in the market economy of our country.It is necessary to strictly control the installation quality of the pipeline for the development of the petrochemical process at the present stage. There is great difficulty of etrochemical piping in the installation, there are many issues that need attention, it is easy to cause security problems, which requires managers control strictly around the pipeline installation links, the pipeline installation works can be standardized in all aspects such as preparatory work, late stage welding, anticorrosion treatment and other aspects, so as to maximize the installation technology of pipeline.

\section{References}

1. Haibo Wang. Exploration On Construction Management Of Petrochemical Process Pipe Installation Project [J]. Standardization of China 2017; (18).

2. Wensong Yang, Yawei Fan. Analysis Of Petrochemical Pipe Installation And Construction Management [J]. Research on the theory of urban construction 2016; (10).

3. Yinbo Chen. Analysis And Measures For Pipeline Construction And Installation In Petrochemical Engineering Process 2015; (36)221-222.

4. Wentao Lin. Study On Construction Management Of Petrochemical Process Pipe Installation Project [J]. Contemporary Chemical Research 2017(2); 67-68. 